\title{
Ocorrência de micotoxicose devido à aflatoxina e desoxinivalenol em rebanho leiteiro no município de Arapongas/PR - relato de caso
}

Luiz Carlos Negri Filho[a], Débora Nayara Augusto Pinto ${ }^{[a]}$, André Victor Romagnoli[a], Marcos Vinicius Vieira ${ }^{[b]}$, João Vitor Veronez ${ }^{[b]}$, Daniela Aparecida da Silva ${ }^{[b]}$, Silvio Manoel Canguçu Rodrigues ${ }^{[b]}$, Camila Bizarro da Silva ${ }^{[c]}$, Maíra Moreira Santos ${ }^{\left[c^{*}\right.}$, Werner Okano ${ }^{[]]}$

\footnotetext{
[a] Programa de Pós-graduação em Saúde e Produção de Ruminantes, Universidade Norte do Paraná (UNOPAR), Arapongas, PR, Brasil

[b] Acadêmicos, Universidade Norte do Paraná (UNOPAR), Arapongas, PR, Brasil

[c] Programa de Pós-graduação em Ciência Animal, Universidade Estadual de Londrina (UEL), Londrina, PR, Brasil
}

*Autor correspondente

e-mail: maira_moreira04@yahoo.com.br

\section{Resumo}

Micotoxinas podem contaminar os alimentos de uso humano e animal, sendo objeto de preocupação na saúde pública. Dentre as micotoxinas, as aflatoxinas são produzidas por fungos toxigênicos Aspergillus flavus, $A$. parasiticuse, $A$. nomius. 0 A. flavus apresenta grande importância na medicina veterinária, pois sua micotoxina acarreta redução do desempenho animal e depressão do sistema imune, tornando os animais mais susceptíveis às infecções. No sistema digestório, pode causar lesões hemorrágicas. Também de importância clínica, há o Desoxinivalenol (DON) ou vomitoxina, uma micotoxina muito estável durante o armazenamento, moagem, processamento e cocção de alimentos produzidos pelo Fusarium graminearum e Fusarium culmorum. Os sinais clínicos de intoxicação pelo DON são vômito, anorexia, gastroenterite, diarreia sanguinolenta, além de imunossupressão e perdas na produção. 0 objetivo deste relato foi descrever a intoxicação por micotoxinas em um rebanho leiteiro do município de Arapongas/PR. Em abril de2015, após a chegada de um novo lote de concentrado e ao ser ofertado a 90 vacas em lactação, houve a rejeição da ração total. Após dois dias de apetite seletivo, os animais voltaram a se alimentar. No dia seguinte, $20 \%$ do rebanho apresentou diarreia sanguinolenta com acentuado decréscimo na produção de leite, registrando uma queda de $25 \%$. Houve a suspensão do fornecimento da ração suspeita e foram adotadas medidas terapêuticas, porém dois animais foram submetidos à eutanásia por não responderem ao tratamento. Foram coletadas amostras de ração de vacas de alta (R1) e de média (R2) produção, assim como de silagem (S), para análise de micotoxinas. As amostras foram analisadas através da técnica de ELISA por competição, para a determinação dos níveis de aflatoxina e DON. As concentrações encontradas de aflatoxinas foram 
$\mathrm{R} 1=2,48 \mu \mathrm{g} / \mathrm{Kg}, \mathrm{R} 2=3,45 \mu \mathrm{g} / \mathrm{Kg}$ e $\mathrm{S}=4,31 \mu \mathrm{g} / \mathrm{Kg}$, e as concentrações de DON foram R1 $=1280 \mu \mathrm{g} / \mathrm{Kg}$, $\mathrm{R} 2=1500 \mu \mathrm{g} / \mathrm{Kg}$ e $\mathrm{S}=550 \mu \mathrm{g} / \mathrm{Kg}$.Os níveis máximos tolerados de aflatoxina e DON para vacas lactantes são de $0 \mu \mathrm{g} / \mathrm{Kg}$ (ausência) e $2000 \mu \mathrm{g} / \mathrm{Kg}$, respectivamente. Considerando a soma R2 e S na dieta total, os animais estavam consumindo cerca de 7,76 $\mu \mathrm{g} / \mathrm{Kg}$ de aflatoxinas e $2050 \mu \mathrm{g} / \mathrm{Kg}$ de DON, níveis acima dos tolerados. Ultrapassando os limites máximos toleráveis, os animais podem apresentar sinais clínicos agudos ou crônicos, dependendo da dosagem ingerida e da categoria animal. Além disso, no momento em que há ingestão dessas micotoxinas pelos mamíferos, ocorre a biotransformação das mesmas, contaminando o leite e seus derivados. Os resultados indicam que os animais ingeriram a aflatoxina e a DON, sendo que a grande maioria apresentou sinais clínicos característicos de intoxicação, podendo considerar que houve sinergismo entre as micotoxinas. 